\footnotetext{
a. Departamento de Producción Animal, Universidad de Buenos Aires, Buenos Aires, Argentina.

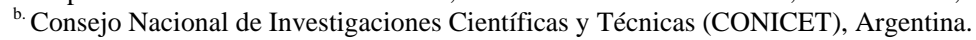

\author{
RODOLFO J. C. CANTET a, ${ }^{a}$ JUAN PEDRO STEIBEL ${ }^{\mathrm{a}}$; ANA N. BIRCHMEIER ${ }^{\mathrm{a}}$ \\ and LUIS F. SANTA COLOMA ${ }^{\mathrm{a}}$

\section{Bayesian estimation of genetic parameters for growth and carcass traits of grass-fed beef cattle by Full Conjugate Gibbs}

\begin{abstract}
Growth and carcass data of Angus cattle were used to estimate heritabilities and genetic and environmental correlations between growth and carcass traits by means of a Bayesian data augmentation (DA) algorithm. Records were taken on 739 Angus steers from 31 sires, during 10 years of a designed progeny test. The cattle were entirely fed on grass during their lifelong. Growth traits evaluated were birth (BW), weaning (WW) and 18month (W18) weights; and carcass traits were the weights of half the carcass (HCW), of hind "pistola" cut (HPW) and of three retail cuts (ECW). The model used for estimation was a multiple trait additive animal model. The prior densities used in the analyses were the multivariate normal for the fixed effects (with very large variances) and for the breeding values, and the inverted Wishart for the additive and environmental covariance matrices. The observed residual vector was augmented with sampled residuals for missing traits. The total number of samples drawn was 200,000. The heritabilities of growth traits increased with age at measure, and those of carcass traits were of sizeable magnitude. Whereas estimates of the genetic correlations were similar to those found in the literature for cattle fed on concentrates, environmental correlations were lower. Additive correlations between growth traits with either the HPW or ECW, were smaller than the correlations between growth characters and HCW.
\end{abstract}

Key Words: data augmentation, multiple traits, growth, carcass, beef cattle, Angus

\title{
Zusammenfassung
}

Titel der Arbeit: Bayessche Schätzung genetischer Parameter der Wachstums- und Schlachtmerkmale von ausschließlich auf Weide gehaltenen Angusrindern

Das Ziel der Untersuchung bestand in der Schätzung von Heritabilitäten sowie genetisch- und umweltbedingten Korrelationen zwischen Wachstum und Schlachtmerkmalen mit Hilfe der Bayesschen Schätzung. Hierfür standen die Datensätze von 739 kastrierten männlichen Tieren der Rasse Angus aus 31 Bullennachkommenschaften zur Verfügung, die in zehnjähriger Nachkommenschaftsprüfung ermittelt wurden. Die ganzjährig auf Weide gehaltenen Rinder wurden ausschließlich mit Gras ernährt. Geschätzte Wachstumsmerkmale waren Geburtsgewicht (BW), Absetzgewicht (WW) und 18-Monate Gewicht. Als Schlachtmerkmale wurden Schlachthälftengewicht (HCW), Hinterviertelgewicht (HPW) und drei Einzelhandels Teilstückgewichte (ECW) ausgewertet. Angewandt wurde ein additives Mehrmerkmalstiermodell. Bei den Wachstumsmerkmalen konnten mit zunehmendem Alter höhere Heritabilitäten geschätzt werden. Die Heritabilitäten der Schlachtmerkmale zeigten mittlere, für alle Merkmale gleich hohe Werte. Die genetischen Korrelationen waren ähnlich denen in der Literatur bei Einsatz von Konzentratfutter beschriebenen Werten. Die phänotypischen Korrelationen waren dagegen niedriger. Für die genetischen Korrelationen zwischen den Wachstumsmerkmalen und HPW bzw. ECW wurden niedrigere Werte als zwischen den Wachstumsmerkmalen und HCW geschätzt.

Schlüsselwörter: Bayessche Schätzung, Mehrmerkmalsmodell, Wachstum, Schlachtmerkmale, Fleischrinder, Angus

\section{Introduction}

Widespread use of genetic evaluation of beef cattle using either data at slaughter or ultrasound measures on live animals, facilitates selecting for carcass traits. In those 
production systems where steers are fed on grass or when there is a restriction in the weight at slaughter, selection for carcass traits may indirectly increase slaughter weight. As GREGORY et al. (1995) and HIROOKA et al. (1996) reported positive genetic correlations between growth and carcass traits of about 0.6 , there may be some scope for selecting on those carcass traits that have smaller correlations with slaughter weight. Also, most estimates of heritabilities and genetic and environmental correlations between growth and carcass traits in beef cattle were obtained from data of steers fattened on concentrate based diets (DINKEL and BUSCH, 1973; WILSON et al., 1976; ARNOLD et al., 1991; GREGORY et al., 1995; HIROOKA et al., 1996). Therefore, accurate estimates of genetic and environmental dispersion parameters for growth and carcass traits in beef cattle raised entirely on pastures are essential for an appropriate genetic evaluation under this production system.

AVILA et al. (1985) reported the genetic evaluation of Angus bulls in a designed progeny test for a beef cattle production system where animals were fed solely with grass. As with most other data sets used to estimate genetic and environmental dispersion parameters in animal breeding, the data set had a fraction of missing trait information for some animals. Missing data affect the precision of estimates, and reduce convergence rates of algorithms used for either REML or Bayesian estimation. VAN TASSELL and VAN VLECK (1996) and SORENSEN (1996) implemented data augmentation algorithms (DA, TANNER and WONG, 1987) to multiple traits animal models with missing records, by means of Gibbs samplers. The objective of this research was to estimate heritabilities and genetic and environmental correlations between growth and carcass traits of Angus beef cattle raised completely on pasture by means of DA.

\section{Materials and methods}

\section{Management of the animals and data collection}

Growth and carcass data used for this study were collected from 1981 to 1990, in a designed progeny test with Angus cattle. Management procedures and data recording were described by AVILA et al. (1985). Calves were born and maintained up to weaning at a property of Universidad de Buenos Aires (UBA), in Laprida, south central Buenos Aires province, Argentina. The animals were the progeny of 31 purebred Angus bulls and commercial heifers. Every year 6 to 7 bulls were proved, and either 1 or 2 sires were repeated the next year to keep the data connected. The herd was artificially inseminated during November and December under a completely randomized scheme of matings. Most calves were born between August and October. The cow-calf herd was kept on native rangeland without any supplemental feeding. After weaning (average age $=252$ days), all males were castrated and taken to another property of UBA in Carlos Casares, western Buenos Aires province, for the fattening phase. The steers were kept on cultivated pastures until they had at least $5 \mathrm{~mm}$ of fat over the ribs, based on visual appraisal. The mean age at slaughter was 28 months and the mean weight was $447 \mathrm{~kg}$. Retail cuts had the external fat completely trimmed. Heifer calves were not included in any analysis. The first group of calves was born in 1981 and the last group of steers were slaughtered in 1990. The traits measured were: 1) Birth weight (BW), 2) Weaning weight (WW), 3) Weight at 18 months of age (W18), 4) Weight of three retail cuts (ECW), 5) Weight of the hind pistola cut (HPW, 
Figure 1), and 6) Half-carcass weight (HCW). Descriptive statistics for all traits, expressed in kg, are shown in Table 1.

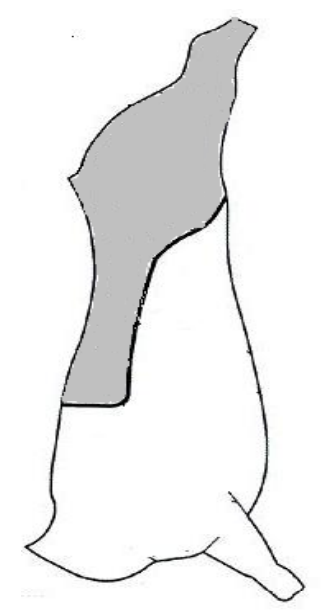

Fig. 1: Hind pistola cut (grey) in the carcass

Table 1

Descriptive statistics for the traits measured

\begin{tabular}{ccccccc}
\hline Trait & $\mathrm{N}$ & Mean & SD & CV & Minimum & Maximum \\
\hline Birth weight & 739 & 30.9 & 4.6 & 15 & 20 & 45 \\
Weaning weight & 561 & 194.5 & 31.2 & 16 & 99 & 305 \\
18 months weight & 405 & 332.1 & 53.4 & 16 & 180 & 472 \\
Weight three retail cuts & 474 & 13.4 & 15 & 11.3 & 9.3 & 18.6 \\
Hind pistola weight & 474 & 50.7 & 51 & 10.1 & 32 & 66 \\
Half carcass weight & 466 & 121.6 & 12.7 & 10.4 & 75 & 154 \\
\hline
\end{tabular}

\section{Data analysis}

\section{Multiple trait animal model with missing data}

The model for the observed data on trait $j$ taken in animal $i$ is as follows:

$$
y_{i j}=\boldsymbol{X}_{i j}{ }^{\prime} \beta_{j}+a_{i j}+e_{i j}
$$

where $y_{i j}, a_{i j}$, and $e_{i j}$, respectively are the observation, the breeding value and the error term, of trait $j(j=1, . .6)$ in animal $i$. The vector $\beta_{j}$ of 'fixed' effects for trait $j$ is related to the observations by a vector $\boldsymbol{X}_{i j}$ ' of known constants. Classification variables included in the vector $\beta$ were sex for BW, and year of birth for all traits. The ages at weaning, at approximately 18 months and at slaughter were used as covariates for WW, W18 and HCW, respectively. The random variable $y_{i j}$ is observed, whereas $a_{i j}$ and $e_{i j}$ are not. The model for the records which were missing for some of the animals was equal to:

$$
y_{M i j}=a_{i j}+e_{i j}
$$

Note that no distinction is made between breeding values and errors in [1] and [2], as in both expressions these random variables are not observed. Let $\boldsymbol{y}$ be the complete (observed and missing) data vector ordered traits within animals, have the following model representation: 


$$
y=X \beta+Z a+e
$$

where the rows of matrix $\boldsymbol{X}$ are equal to $\boldsymbol{X}_{i j}{ }^{\prime}$, if trait $j$ of animal $i$ is observed, or they are equal to vectors of zeroes otherwise. The matrix $\boldsymbol{Z}$ relates records to breeding values and has rows with all elements equal to 0 , except for a 1 in the column associated with $a_{i j}$, whenever trait $y_{i j}$ is observed. The vector $\boldsymbol{a}$ contains all breeding values and the vector $\boldsymbol{e}$ contain all errors, under either [1] or [2]. Under these specifications, the covariance matrix of breeding values can be written as:

$$
\operatorname{Var}(\boldsymbol{a})=\left[\begin{array}{ccccc}
\boldsymbol{g}_{1,1} \boldsymbol{A} & \boldsymbol{g}_{1,2} \boldsymbol{A} & \ldots & \boldsymbol{g}_{1,5} \boldsymbol{A} & \boldsymbol{g}_{1,6} \boldsymbol{A} \\
\boldsymbol{g}_{2,1} \boldsymbol{A} & \boldsymbol{g}_{2,2} \boldsymbol{A} & \ldots & \boldsymbol{g}_{2,5} \boldsymbol{A} & \boldsymbol{g}_{2,6} \boldsymbol{A} \\
\ldots & \ldots & \ldots & \ldots & \ldots \\
\boldsymbol{g}_{5,1} \boldsymbol{A} & \boldsymbol{g}_{5,2} \boldsymbol{A} & \ldots & \boldsymbol{g}_{5,5} \boldsymbol{A} & \boldsymbol{g}_{5,6} \boldsymbol{A} \\
\boldsymbol{g}_{6,1} \boldsymbol{A} & \boldsymbol{g}_{6,2} \boldsymbol{A} & \ldots & \boldsymbol{g}_{6,5} \boldsymbol{A} & \boldsymbol{g}_{6,6} \boldsymbol{A}
\end{array}\right]=\boldsymbol{G}_{0} \otimes \boldsymbol{A}
$$

where $g_{, j j}$, is the additive genetic covariance between traits $j$ and $j$ ', if $j \neq j$ ', and equal to the variance of trait $j$ if $j=j$ '. The matrix of genetic (co)variances $\boldsymbol{G}_{0}=\left[g_{j j}\right.$ '] is of order $6 \times 6$, and $\boldsymbol{A}(q \times q)$ is the additive relationship matrix among sires, grandsires and male progeny. As dams were not identified, no maternal effects enter into $\boldsymbol{G}_{0}$. The variance of the error terms is equal to $\boldsymbol{R}_{0} \otimes \boldsymbol{I}$, where $\boldsymbol{R}_{0}=\left[r_{j j}\right]$ and $r_{j j}$, are the environmental (co)variances between traits $j$ and $j$ '.

\section{Prior densities}

The prior distribution of the fixed effects was taken to be multivariate normal $\beta \sim N$ ( 0 , $\boldsymbol{K})$, with the diagonal covariance matrix $\boldsymbol{K}$ having very large diagonal elements $\left(\boldsymbol{K}_{i i}>\right.$ $10^{8}$ ) in order to avoid improper posterior densities (HOBERT and CASELLLA, 1996). Breeding values were assumed to be distributed a priori as $\boldsymbol{a} \sim N\left(\mathbf{0}, \boldsymbol{G}_{0} \otimes \boldsymbol{A}\right)$. Under these specifications, the distribution for the observed and the missing data is $\boldsymbol{y} \mid \boldsymbol{a} \sim N\left(\boldsymbol{X} \boldsymbol{\beta}+\boldsymbol{Z a}, \boldsymbol{R}_{\mathbf{0}} \otimes \boldsymbol{I}\right)$. Inverted Wishart (IW) densities were used for both $\boldsymbol{G}_{0}$ and $\boldsymbol{R}_{0}: \boldsymbol{G}_{0} \sim$ IW $\left(\boldsymbol{G}_{0}{ }^{*}, n_{A}\right)$ and $\boldsymbol{R}_{0} \sim$ IW $\left(\boldsymbol{R}_{0}{ }^{*}, n_{e}\right)$. The hyperparameters are the prior variances $\left(\boldsymbol{G}_{0}{ }^{*}\right.$ and $\left.\boldsymbol{R}_{0}{ }^{*}\right)$, and the prior degrees of belief $\left(n_{A}, n_{e}\right)$. The covariance matrices $\boldsymbol{G}_{0}{ }^{*}$ and $\boldsymbol{R}_{0}{ }^{*}$ were taken to be equal to the Restricted Maximum Likelihoood (PATTERSON and THOMPSON, 1971) estimates of $\boldsymbol{G}_{0}$ and $\boldsymbol{R}_{0}$, respectively, using the Expectation-Maximization algorithm (EM, DEMPSTER et al., 1977), as described in HENDERSON (1984). The degrees of belief were set to $n_{A}=n_{e}=10$, so as to represent uncertain knowledge of the values for $\boldsymbol{G}_{0}{ }^{*}$ and $\boldsymbol{R}_{0}{ }^{*}$, respectively. Except for the prior distribution of the fixed effects, the prior densities employed here are similar to those used by VAN TASSELL and VAN VLECK (1996) and by SORENSEN (1996) while implementing data augmentation (DA, TANNER and WONG, 1987) algorithms for multiple traits.

\section{Multiple trait data augmentation}

Using the representation [1]-[2] the DA sampler for multiple traits of VAN TASSELL and VAN VLECK (1996) and SORENSEN (1996), can be written in a straightforward manner. Consider the following linear system: 


$$
\left[\begin{array}{cc}
X^{\prime}\left(R^{-1} \otimes I\right) X & X^{\prime}\left(R^{-1} \otimes I\right) Z \\
Z^{\prime}\left(R^{-1} \otimes I\right) X & Z^{\prime}\left(R^{-1} \otimes I\right) Z+G_{0} \otimes A^{-1}
\end{array}\right]\left[\begin{array}{l}
\hat{\beta} \\
\hat{a}
\end{array}\right]=\left[\begin{array}{l}
X^{\prime}\left(R^{-1} \otimes I\right) y \\
Z^{\prime}\left(R^{-1} \otimes I\right) y
\end{array}\right]
$$

Then, conditional on $\boldsymbol{K}, \boldsymbol{G}_{0}$ and $\boldsymbol{R}_{0}$, the joint posterior density of $\boldsymbol{\beta}$ and $\boldsymbol{a}$ is equal to:

$$
\left[\begin{array}{l}
\beta \\
a
\end{array}\right] \sim N\left(\left[\begin{array}{l}
\hat{\beta} \\
\hat{a}
\end{array}\right],\left[\begin{array}{cc}
X^{\prime}\left(R^{-1} \otimes I\right) X & X^{\prime}\left(R^{-1} \otimes I\right) Z \\
Z^{\prime}\left(R^{-1} \otimes I\right) X & Z^{\prime}\left(R^{-1} \otimes I\right) Z+G_{0} \otimes A^{-1}
\end{array}\right]^{-1}\right)
$$

The normal density [4] allows the sampling of parameters either one by one or by block (VAN TASSELL and VAN VLECK, 1996). Let $\boldsymbol{S}$ be

$$
\boldsymbol{S}=\left[\begin{array}{ccccc}
\boldsymbol{a}_{1}{ }^{\prime} \boldsymbol{A}^{-1} \boldsymbol{a}_{1} & \boldsymbol{a}_{1}{ }^{\prime} \boldsymbol{A}^{-1} \boldsymbol{a}_{2} & \ldots & \boldsymbol{a}_{1}{ }^{\prime} \boldsymbol{A}^{-1} \boldsymbol{a}_{5} & \boldsymbol{a}_{1}{ }^{\prime} \boldsymbol{A}^{-1} \boldsymbol{a}_{6} \\
\boldsymbol{a}_{2}{ }^{\prime} \boldsymbol{A}^{-1} \boldsymbol{a}_{1} & \boldsymbol{a}_{2}{ }^{\prime} \boldsymbol{A}^{-1} \boldsymbol{a}_{2} & \ldots & \boldsymbol{a}_{2}{ }^{\prime} \boldsymbol{A}^{-1} \boldsymbol{a}_{5} & \boldsymbol{a}_{2}{ }^{\prime} \boldsymbol{A}^{-1} \boldsymbol{a}_{6} \\
\ldots & \ldots & \ldots & \ldots & \ldots \\
\boldsymbol{a}_{5}{ }^{\prime} \boldsymbol{A}^{-1} \boldsymbol{a}_{1} & \boldsymbol{a}_{5}{ }^{\prime} \boldsymbol{A}^{-1} \boldsymbol{a}_{2} & \ldots & \boldsymbol{a}_{5}{ }^{\prime} \boldsymbol{A}^{-1} \boldsymbol{a}_{5} & \boldsymbol{a}_{5}{ }^{\prime} \boldsymbol{A}^{-1} \boldsymbol{a}_{6} \\
\boldsymbol{a}_{6}{ }^{\prime} \boldsymbol{A}^{-1} \boldsymbol{a}_{1} & \boldsymbol{a}_{6}{ }^{\prime} \boldsymbol{A}^{-1} \boldsymbol{a}_{2} & \ldots & \boldsymbol{a}_{6}{ }^{\prime} \boldsymbol{A}^{-1} \boldsymbol{a}_{5} & \boldsymbol{a}_{6}{ }^{\prime} \boldsymbol{A}^{-1} \boldsymbol{a}_{6}
\end{array}\right]
$$

Then, after SORENSEN (1996), the posterior density of $\boldsymbol{G}_{0}$ is as follows

$$
\boldsymbol{G}_{0} \mid \boldsymbol{G}_{0}^{*} \sim \operatorname{IW}_{6}\left(\left(\boldsymbol{G}_{0}^{*}-1+\boldsymbol{S}\right)^{-1}, n_{A}+q\right)
$$

In a similar fashion let

$$
\boldsymbol{T}=\left[\begin{array}{ccccc}
\boldsymbol{e}_{1} \boldsymbol{e}_{1} & \boldsymbol{e}_{1}^{\prime} \boldsymbol{e}_{2} & \ldots & \boldsymbol{e}_{1}^{\prime} \boldsymbol{e}_{5} & \boldsymbol{e}_{1}^{\prime} \boldsymbol{e}_{6} \\
\boldsymbol{e}_{2} \boldsymbol{e}_{1} & \boldsymbol{e}_{2} \boldsymbol{e}_{2} & \ldots & \boldsymbol{e}_{2}^{\prime} \boldsymbol{e}_{5} & \boldsymbol{e}_{2}^{\prime} \boldsymbol{e}_{6} \\
\ldots & \ldots & \ldots & \ldots & \ldots \\
\boldsymbol{e}_{5} \boldsymbol{e}_{1} & \boldsymbol{e}_{5} \boldsymbol{e}_{2} & \ldots & \boldsymbol{e}_{5}^{\prime} \boldsymbol{e}_{5} & \boldsymbol{e}_{5}^{\prime} \boldsymbol{e}_{6} \\
\boldsymbol{e}_{6} \boldsymbol{e}_{1} & \boldsymbol{e}_{6} \boldsymbol{e}_{2} & \ldots & \boldsymbol{e}_{6}^{\prime} \boldsymbol{e}_{5} & \boldsymbol{e}_{6}^{\prime} \boldsymbol{e}_{6}
\end{array}\right]
$$

so that:

$$
\boldsymbol{R}_{0} \mid \boldsymbol{R}_{0}^{*} \sim \operatorname{IW}_{6}\left(\left(\boldsymbol{R}_{0}^{*}-1+\boldsymbol{T}\right)^{-1}, n_{e}+n\right)
$$

Whenever records within an individual were missing, the errors (as represented in [2]) were sampled from:

$$
\boldsymbol{e}_{m} \mid \boldsymbol{e}_{o} \sim N\left(\boldsymbol{R}_{m o} \boldsymbol{R}_{o o}{ }^{-1} \boldsymbol{e}_{o}, \boldsymbol{R}_{m m}-\boldsymbol{R}_{m o} \boldsymbol{R}_{o o}{ }^{-1} \boldsymbol{R}_{o m}\right)
$$

where $\boldsymbol{R}_{m m}, \boldsymbol{R}_{o o}$ and $\boldsymbol{R}_{m o}$ are the variance of $\boldsymbol{e}_{m}$, the variance of $\boldsymbol{e}_{o}$, and the covariance between $\boldsymbol{e}_{m}$ and $\boldsymbol{e}_{o}$, respectively. Besides, $\boldsymbol{e}_{o}=\boldsymbol{y}_{o}-\boldsymbol{X} \beta-\boldsymbol{a}$, with $\beta$ and $\boldsymbol{a}$ being sampled from the normal density [4]. Thus, missing errors $\boldsymbol{e}_{m}$ were sampled using the DA algorithm of TANNER and WONG (1987). In brief, the implementation of DA was as follows:

1. Built and solve equations [3].

2. Sample $\beta$ and $\boldsymbol{a}$ from [4].

3. Calculate the observed errors as $\boldsymbol{e}_{o}=\boldsymbol{y}_{o}-\boldsymbol{X} \boldsymbol{\beta}-\boldsymbol{Z} \boldsymbol{a}$.

4. Sample the missing errors from distribution [9]. 
5. Calculate $\boldsymbol{S}$ and $\boldsymbol{T}$.

6. Sample $\boldsymbol{G}_{0}$ from [6] and $\boldsymbol{R}_{0}$ from [8], and go back to 1 .

From an initial sample of size 20,000, convergence was assessed with the diagnostics suggested by RAFTERY and LEWIS (1992) for the median (50-percentile). The degree of accuracy was set equal to 0.01 , and the probability of attaining this degree of accuracy was set to 0.90 . The total number of Monte Carlo samples drawn from a single chain was then equal to 200,000 .

\section{Results and Discussion}

Diagonal elements of $\boldsymbol{G}_{0}$ and $\boldsymbol{R}_{0}$ were expressed as heritabilities, whereas off diagonal elements of $\boldsymbol{G}_{0}$ were expressed as additive correlations and those of $\boldsymbol{R}_{0}$ were expressed as environmental correlations. The estimates of the posterior means of heritabilities, additive and environmental correlations are displayed in Table 2, and posterior medians of the same parameters are shown in Table 3. The estimates of the posterior means and medians were noticeably similar for all parameters. Posterior modes were not reported here but they were similar to both means and medians.

Table 2

Posterior means of heritabilities (on main diagonal), of additive correlations (above main diagonal) and of environmental correlations (below main diagonal)

\begin{tabular}{ccccccc}
\hline & BW & WW & W18 & ECW & HPW & HCW \\
\hline BW & 0.196 & 0.441 & 0.495 & 0.442 & 0.516 & 0.532 \\
WW & 0.207 & 0.318 & 0.722 & 0.61 & 0.572 & 0.668 \\
W18 & 0.248 & 0.634 & 0.427 & 0.651 & 0.662 & 0.791 \\
ECW & 0.134 & 0.511 & 0.541 & 0.448 & 0.898 & 0.838 \\
HPW & 0.076 & 0.543 & 0.593 & 0.757 & 0.464 & 0.897 \\
HCW & 0.156 & 0.512 & 0.613 & 0.625 & 0.736 & 0.463 \\
\hline
\end{tabular}

Table 3

Posterior medians of heritabilities (on main diagonal), of additive correlations (above main diagonal) and of environmental correlations (below main diagonal)

\begin{tabular}{ccccccc}
\hline & BW & WW & W18 & ECW & HPW & HCW \\
\hline BW & 0.197 & 0.447 & 0.498 & 0.453 & 0.533 & 0.552 \\
WW & 0.204 & 0.331 & 0.745 & 0.654 & 0.632 & 0.715 \\
W18 & 0.241 & 0.637 & 0.442 & 0.688 & 0.708 & 0.822 \\
ECW & 0.143 & 0.521 & 0.552 & 0.459 & 0.912 & 0.857 \\
HPW & 0.079 & 0.557 & 0.604 & 0.756 & 0.474 & 0.908 \\
HCW & 0.154 & 0.516 & 0.613 & 0.624 & 0.736 & 0.474 \\
\hline
\end{tabular}

Table 4

Posterior variances of heritabilities (on main diagonal), additive (above main diagonal) and environmental correlations (below main diagonal)

\begin{tabular}{ccccccc}
\hline & BW & WW & W18 & ECW & HPW & HCW \\
\hline BW & 0.0025 & 0.0286 & 0.0252 & 0.0244 & 0.0223 & 0.0202 \\
WW & 0.016 & 0.0046 & 0.0113 & 0.02 & 0.0214 & 0.0158 \\
W18 & 0.016 & 0.007 & 0.0066 & 0.0166 & 0.0171 & 0.0093 \\
ECW & 0.019 & 0.012 & 0.014 & 0.0065 & 0.0021 & 0.0052 \\
HPW & 0.019 & 0.012 & 0.012 & 0.004 & 0.0066 & 0.0019 \\
HCW & 0.018 & 0.01 & 0.008 & 0.009 & 0.005 & 0.0063 \\
\hline
\end{tabular}

Posterior means and medians of genetic and environmental correlations between growth and carcass traits increased as the age of the weight measure increased (Tables 2 and 3). Posterior variances are displayed in Table 4.

Graphs of some selected posterior densities can be seen in Figures 2, 3 and 4, as most 
posterior distributions looked alike. The graphs show that, although means, medians and modes were similar, posterior distributions of genetic parameters for growth and carcass traits in beef cattle display some skewness.

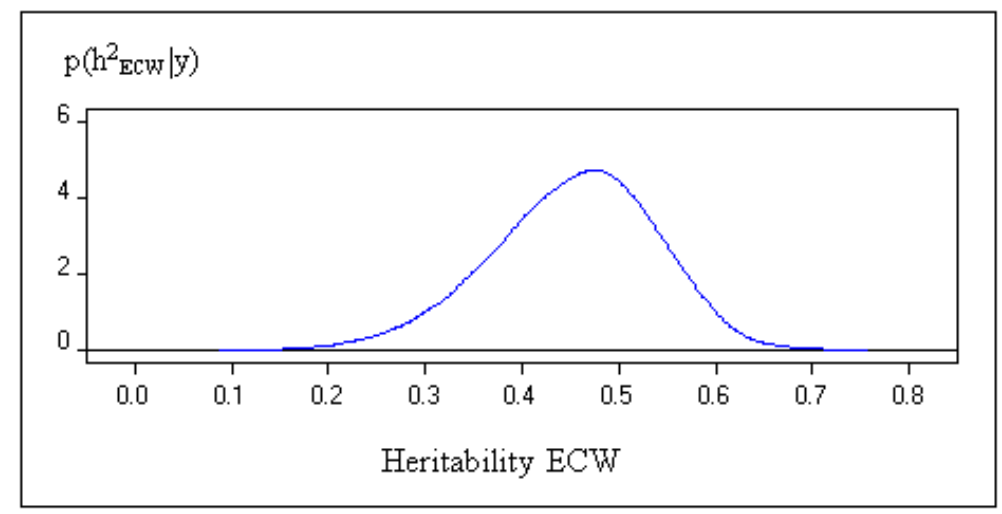

Fig. 2: MCMC estimate of the posterior density of heritability of ECW

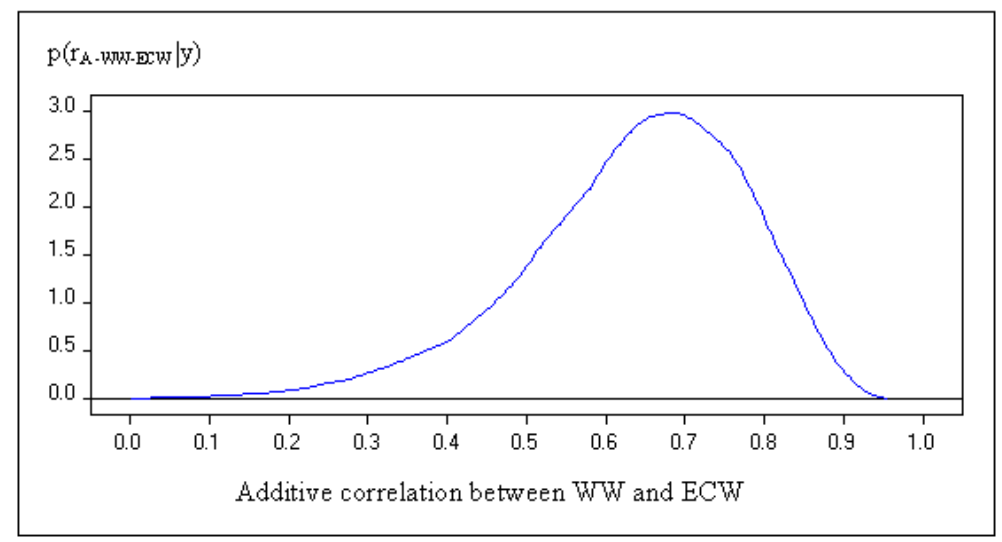

Fig. 3: MCMC estimate of the posterior density of the additive correlation between WW and ECW

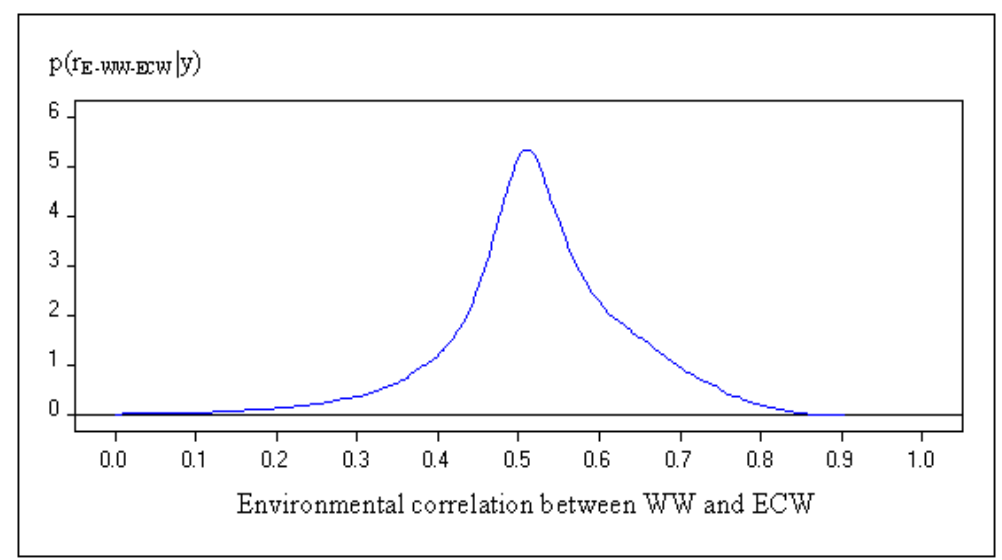

Fig. 4: MCMC estimate of the posterior density of the environmental correlation between WW and ECW

The posterior means of additive correlations among growth traits were $0.441,0.495$ and 0.722 for BW-WW, BW-W18, and WW-W18, respectively. Corresponding averages of the estimates of the genetic correlations in males reviewed by MOHIUDDIN (1993) were 0.47, 0.64 and 0.88. Environmental correlations between BW and carcass traits were much lower than the correlations between WW or W18 with the carcass measures. The trend of increased genetic and environmental 
correlations between growth and carcass traits with age at measure, was also observed by GREGORY et al. (1995) with steers from different purebreds and composite populations. It is worth mention than the additive correlations between ECW or HPW with growth traits were smaller than the genetic correlations between HCW with BW, WW and W18. In production systems were cattle is fattened on grass and/or there is an optimum weight at slaughter, selection for growth may have to be restricted. Therefore, selecting for hind pistola or retail cuts would decrease the effect of indirect selection for growth than selecting for carcass weight.

The observation that environmental correlations between BW and carcass traits were much lower than the correlations between WW or W18 with the carcass measures, may reflect the fact that calves were born and raised in a very different environment (locations) than the one used for the fattening phase, the latter having better grass quality and larger pasture availability. A supporting evidence is that the environmental correlations between BW and either WW or W18, were about one third (0.20 to 0.25) of the magnitude of the environmental correlation between these two traits (0.635). The estimated environmental correlations are similar to the averages of the estimates reviewed by MOHIUDDIN (1993), which were equal to 0.16 for BW-WW, 0.14 for BW-W18 and 0.61 for WW-W18. Additive correlations among the three carcass weight measures were high (about 0.9), being the environmental correlations of smaller magnitude (0.62 to 0.75 ).

The prevailing approach to estimating genetic and environmental parameters for growth and carcass traits has been to report point estimates, either by using quadratic estimators with approximate standard errors (DINKEL and BUSCH, 1973; WILSON et al., 1976; GREGORY et al., 1995) or by REML (ARNOLD et al., 1991; HIROOKA et al., 1996). Therefore, it is usually difficult to know how precise those estimates were. Alternatively, the Bayesian method used here allowed obtaining Monte Carlo estimates of the posterior variances, as well as characterizing the posterior distribution of the estimated genetic parameters. In general posterior variances suggest that heritabilities were estimated with reasonable accuracy (16 to $25 \%$ in terms of coefficients of variation), followed by additive correlations (5 to 37\% C.V.) and environmental correlations (9 to $174 \% \mathrm{C}$.V.), with those involving BW being the least accurate (52 to $174 \%)$.

\section{Acknowledgments}

This research was supported by grants of Secretaria de Ciencia y Técnica, UBA (UBACyT G035 - 2001-2003), Consejo Nacional de Investigaciones Científicas y Técnicas (PIP 0934-98) and Agencia Nacional de Ciencia y Tecnología (FONCyT PIC 08-09502) of Argentina.

\section{References}

ARNOLD, J.W.; BERTRAND, J.K.; BENYSHEK, L.L.; LUDWIG, C.:

Estimates of genetic parameters for live animal ultrasound, actual carcass data, and growth traits in beef cattle. J. Anim. Sci. 69 (1991), 985-992

AVILA, V.S DE; MANFREDI, E.J.; BIDART, J.B.; SANTA COLOMA, L.F. DE.:

Genetic evaluation of Aberdeen Angus sires for growth traits. (Evaluación genética de padres Aberdeen Angus para caracteres de crecimiento). Revista Argentina de Producción Animal. 5 (1985), 79-87 
DEMPSTER, A.P.; LAIRD, N.M.; RUBIN, D.B.:

Maximum likelihood from incomplete data via the EM algorithm. J. Roy. Statist. Soc. Ser. B. 39 (1977), 1-55

DINKEL, C.A.; BUSCH, D.A.:

Genetic parameters among production, carcass composition and carcass quality traits of beef cattle. J. Anim. Sci. 36 (1973), 832-846

GREGORY, K.E.; CUNDIFF, L.V.; KOCH, R.M.:

Genetic and phenotypic (co)variances for growth and carcass traits of purebreed and composite populations of beef cattle. J. Anim.Sci. 73 (1995), 1920-1926

HENDERSON, C.R.: Applications of Linear Models in Animal Breeding. University of Guelph, Guelph, 1984

HIROOKA, H.; GROEN, A. F.; MATSUMOTO, M.

Genetic parameters for growth and carcass traits in Japanese Brown cattle estimated from field records. J. Anim. Sci. 74 (1996), 2112-2116.

HOBERT, J. P.; CASELLA, G.

The effect of improper priors on Gibbs sampling in hierarchical linear mixed models. J. Amer. Stat. Assoc. 91 (1996), 1461-1473.

MOHIUDDIN, G.:

Estimates of genetic and phenotypic parameters of some performance traits in beef cattle. Anim. Breed. Abs. 61 (1993), 495-522

PATTERSON, H.D.; THOMPSON, R.:

Recovery of inter-block information when block sizes are unequal. Biometrika 58 (1971) 545-554

RAFTERY, A.E.; LEWIS, S.M.:

How many iterations in the Gibbs sampler? In: Bayesian Statistics 4, pp. 763-773. J.M. BERNARDO et al., eds. Oxford University Press, Oxford (1992)

SEARLE, S.R.; CASELLA, G.; MCCULLOCH, C.E.:

Variance Components. John Willey \& Sons, New York (1992)

SORENSEN, D.A.:

Gibbs sampling in quantitative genetics. Department of Breeding and Genetics. Danish Institute of Animal Science. Internal Report 82, Foulum (1996)

TANNER, M. A.; WONG, W. H.:

The calculation of posterior distributions by data augmentation. J. Amer. Stat. Assoc. 82 (1987), 528550

VAN TASSELL, C.P.; VAN VLECK, L.D.:

Multiple-trait Gibbs sampler for animal models: flexible programs for Bayesian and likelihood-based (co)variance component inference. J. Anim. Sci. 74 (1996), 2586-2597

WILSON, L.L.; MCCURLEY, J.R.; ZIEGLER, J.H.; WATKINS, J.L.:

Genetic parameters of live and carcass characters from progeny of Polled Hereford sires and AngusHolstein cows. J. Anim. Sci. 43 (1976), 569-576

Received: 2003-05-09

Accepted: 2003-07-30

Author's addresses

Prof. RODOLFO J. C. CANTET, Ph.D.

Universidad de Buenos Aires, Facultad de Agronomía, Departamento de Producción Animal, Av. San Martín 4453, C1417DSQ Buenos Aires, Argentina, and Consejo Nacional de Investigaciones Científicas y Técnicas (CONICET), Argentina

Ing. Agr. MSc. JUAN PEDRO STEIBEL

Universidad de Buenos Aires, Facultad de Agronomía, Departamento de Producción Animal, Av. San Martín 4453, C1417DSQ, Buenos Aires, Argentina

Ing. Agr. MSc. ANA N. BIRCHMEIER

Universidad de Buenos Aires, Facultad de Agronomía, Departamento de Producción Animal, Av. San Martín 4453, C1417DSQ, Buenos Aires, Argentina

Prof. LUIS F. DE SANTA COLOMA, Ing. Agr.

Universidad de Buenos Aires, Facultad de Agronomía, Departamento de Producción Animal, Av. San Martín 4453, C1417DSQ, Buenos Aires, Argentina 